\title{
UN ACERCAMIENTO AL ESTUDIO DE LOS DESARROLLOS HABITACIONALES CERRADOS Y SU DISTRIBUCIÓN GEOGRÁFICA EN EL ESPACIO PERIURBANO DE TIJUANA, BAJA CALIFORNIA
}

\author{
An approach to the study of closed housing developments \\ and their geographical distribution in space periurban Tijuana, \\ Baja California
}

\author{
Elizabeth Méndez Mungaray ${ }^{1}$
}

Recibido: 16/02/2013 Aceptado: 23/05/2013

Resumen. Ante el surgimiento de desarrollos habitacionales cerrados de diferentes caracteristicas en el espacio periurbano de la ciudad de Tijuana, la población residente se ha visto afectada debido a su distribución geográfica y a otros distintos factores sociales. Mediante el análisis del proceso de conformación de los desarrollos habitacionales, registrados entre 1990 y 2010, más la revisión documental, estadística y el análisis geográfico (Sistemas de Información Geográfica), se ha podido comprender de qué manera esa distribución está influenciando la calidad de vida de los residentes en dichos espacios. Se ha observado que los desarrollos habitacionales cerrados en el periurbano se han ido conformado cada vez más con un mayor número de viviendas de dimensiones reducidas, y que su distribución geográfica se presenta en zonas cada vez más alejadas de la franja periurbana, donde aún se carece de una suficiente infraestructura urbana y servicios.

Palabras clave: Desarrollos habitacionales cerrados, periurbano, uso residencial, vivienda.

Abstract. With the emergence of closed housing developments of different characteristics in space suburban city of Tijuana, the resident population has been affected due to their geographical distribution and other factors. By analyzing the process of shaping housing developments between 1990 and 2010, plus the document review, statistical and geographical analysis (Geographic Information Systems) has been able to understand how this distribution is influencing the quality of residents living in those spaces. It has been observed that the closed housing developments in suburban conform; increasingly larger numbers of small sized homes and their geographical distribution is presented in increasingly remote areas of the strip where peri still lacks sufficient infrastructure and services.

Key words: Closed housing developments, suburban, residential, housing.

(') Alumna del programa de doctorado "Asentamientos Humanos y Actividades Económicas" (UNED). Blvd. Abelardo L. Rodríguez 2925, Zona del Río. Tijuana, B.C. 22320, México. E-mail: emendez@colef.mx 


\section{EL ESPACIO RESIDENCIAL DEL PERIURBANO}

\subsection{Transformaciones residenciales en el espacio periurbano}

Las diferencias entre las actividades, la composición social de la población, las rentas del suelo y otros factores, han definido los diversos enfoques teóricos que explican la estructura urbana. Sobre todo mediante el análisis e interpretación de los modelos de organización y función del espacio intraurbano (Zárate, 1991). Parte de las reacciones sobre los modelos concéntricos tradicionales de estructuración fueron los de las áreas sociales que se aplican al estudio de la diferenciación residencial (MUY CONFUSO). En 1949 Shevky y Williams estudiaron la ciudad de Los Ángeles, y Bell (1955) la de San Francisco, en Estados Unidos ${ }^{2}$. Estos autores señalaban que en la estructura intraurbana la variación de factores socioeconómicos, étnicos, culturales y de estatus dentro del ciclo de vida poblacional influian de manera importante en la diferenciación intraurbana. En sus análisis la presencia de los distintos factores son considerados a partir de su intensidad.

Durante las últimas décadas del siglo $\mathrm{XX}$, autores como Griffin y Ford (1980) enfocaron el análisis de nuevas centralidades y explicaron que los centros compactos de servicios especializados y de alta accesibilidad mostraban una notable tendencia en cuanto a su crecimiento. Sin embargo, el explosivo aumento poblacional detonó también una expansión moderna de las clases altas hacia mejores espacios residenciales suburbanos; los cuales contaban con la presencia de corredores comerciales y gozaban de toda clase de servicios.

En el estudio de las áreas de transición rural-urbano relacionadas con las metrópolis, la periurbanización corresponde a un proceso de consolidación de esta franja que lleva consigo varios cambios en cuanto al uso del suelo; como la creación de nuevos espacios residenciales y la relocalización de actividades productivas, asi como nuevas configuraciones en el transporte y de vías de comunicación. Por su parte la población de características más rurales de esta franja tiende a trabajar en la parte central, trasladándose desde el área rural de residencia. A este fenómeno se le ha llamado rurbanización (Bauer y Roux, 1976) y ciudad difusa (Monclús, 2000).
La visión de una ciudad descentralizada, dispersa o difusa, con diferentes procesos sociales, económicos, tecnológicos y culturales, ha dejado atrás a la ciudad compacta tradicional. Ahora se impone el modelo anglosajón y que se ha reproducido también en otras ciudades (Firshman, 1994) del mundo. De esta manera, en las últimas décadas gran parte de los estudios de las metrópolis y las grandes ciudades latinoamericanas coinciden en afirmar que las estrategias macroeconómicas de liberación y desregulación, por parte de los gobiernos y en un contexto de globalización y otros procesos endógenos, han privilegiado la acción del capital privado. Esto ha producido cambios profundos en la restructuración urbana, bajo los cuales se intensifican y expanden fenómenos como las nuevas modalidades de expansión periurbana. Las estructuras policéntricas y otros efectos, como la segregación residencial, la polarización, la desigualdad social, la fragmentación y otros, han configurado nuevos procesos de expansión territorial (De Mattos, 2002).

Los estudios más importantes del proceso urbanístico suburbano corresponden a los de las grandes ciudades norteamericanas, en las que desde principios del siglo pasado se fueron observando procesos de concentración de actividades financieras, de toma de decisiones y comerciales en general. Lo que condujo a la saturación central de los servicios, como los de la vivienda. Con el tiempo estas condiciones dieron lugar a un proceso de desconcentración selectiva lo que se manifestó en el desarrollo de los suburbs norteamericanos. Los suburbs fueron constituidos por amplias zonas habitacionales con estructura horizontal, generalmente asentadas sobre "áreas verdes" y alrededor de las metrópolis. Son fenómenos que han contribuido también a la concepción de las nuevas periferias funcionales en otras partes del mundo (Ávila, 2001) ${ }^{3}$.

La función residencial del periurbano, en general, tiene su mayor representatividad en la forma unifamiliar, referida a formas de desarrollo de baja densidad y de alto consumo de suelo. Esto debido en parte a las fuerzas del mercado del suelo, de producción y de relaciones sociales que ejercen presión sobre el tipo y la intensidad en la ocupación. No se trata de un fenómeno nuevo, pero existen factores recientes que lo impulsan. Como son las aglomeraciones y las crisis en las ciudades, el desarrollo de los transportes y el aprecio sobre la naturaleza (Fernández, 1985). A su vez, estos aspectos son aprovechados por agentes económicos del sector inmobiliario y de la construcción para influir en el rumbo del desarrollo urbano.

(2) Autores citados en (Zárate, 1991).

(3) Un importante número de las grandes ciudades de Estados Unidos ha desarrollado una economía muy ligada al fenómeno de la periurbanización. Varios autores (Castells,1990; Dézert,1992; Castells y Hall,1994) mencionan algunos de los factores más importantes: la contra-urbanización, el desarrollo de los medios de transporte y proliferación de rutas terrestres rápidas, el desarrollo de grandes superficies comerciales (malls), la descentralización de los campus o institutos universitarios ligados a la investigación, el crecimiento de las zonas suburbanas ocupadas por familias jóvenes (técnicos, académicos e ingenieros, ligados a las empresas de alta tecnología), asi como la preferencia general por el hábitat natural. 
Entre los estudios que tratan las transformaciones de las ciudades, ya sea relacionadas directa o indirectamente con los procesos de la globalización, destacan los que tratan los cambios en la organización y funcionalidad dirigidas a una base económica terciarizada. Sobre todo con apertura de las economías nacionales y que se traduce en la competitividad entre los mercados. Pero ya no se limitan a países individuales, sino que aumenta la apertura a escalas regional e internacional. De manera que la "competitividad es cada vez más resultado de las relaciones y redes y menos de las formas tradicionales de productividad" (Veltz, 2000).

Así, en décadas recientes se experimentaron cambios profundos en las periferias residenciales. Cambios relacionados con fenómenos contemporáneos de reestructuración socioeconómica y de comunicación de las nuevas tecnologías, así como de procesos locales y globales, donde el papel del capital privado ha sido preponderante. En algunas transformaciones se han involucrado fenómenos tales como: la movilidad residencial de clases altas y de otros estratos hacia las periferias; la construcción de complejos de vivienda tanto unifamiliar como multifamiliar dirigidos a diferentes niveles sociales; invasión de terrenos no ocupados, en esta franja, por parte de grupos de clases bajas y/o migrantes; las grandes obras de infraestructura como aeropuertos o vías de comunicación principales,reoresentan hechos y procesos que facilitan el desarrollo de actividades productivas y que, en conjunto, atraen la ubicación de toda clase de usos del suelo (Aguilar, 2006).

Algunas de las transformaciones más importantes son las siguientes:

- el tipo de movilidad de la población por razones laborales no solo se realiza del centro a la periferia, sino de periferia a periferia y de la periferia al centro;

- $\quad$ surgimiento de nuevas centralidades o subcentros alternativos al centro tradicional;

- mayor presencia de grupos pobres en asentamientos periurbanos y/o ilegales, producto de la salida del centro o de la llegada de inmigrantes;

- mercado de vivienda segregado con grandes diferenciaciones entre viviendas populares y exclusivos desarrollos residenciales;

- gran incremento del número de automotores que facilitan el desplazamiento periurbano y consecuentemente la deficiencia en el transporte público;

- segregación y desplazamiento paulatino de los sistemas productivos, al pasar de sectores primarios a industriales y terciarios predominantes, es decir, a economías mixtas;
- mezcla de usos de esparcimiento con usos para actividades marginales de depósito de desechos de la ciudad, y perdidas de espacio natural (contaminación, deforestación, ocupación urbana, etcétera).

\subsection{Los desarrollos habitacionales cerrados en el periurbano}

Algunas ciudades latinoamericanas, consideradas como metrópolis, han sido objeto de complejos procesos locales e internacionales que transforman continuamente el uso del espacio urbano, en especial el de las periferias. Situación que se refleja en el uso intensivo del suelo, sobre todo para la construcción masiva de viviendas en conjuntos densos y con diversas características. Entre las que destacan el cercamiento perimetral de las viviendas y el control de sus accesos, esto bajo los conceptos de exclusividad y seguridad, así como el del contacto con la naturaleza. Elementos que, en general, podrian ofrecer una mayor calidad de vida a sus residentes.

A estos desarrollos habitacionales se les puede definir como asentamientos privados, muchas veces construidos fuera de la red pública. Se encuentran físicamente separados por alguna frontera material (perímetro delimitado por algún tipo de cercamiento y con acceso controlado), y sobre la base de la producción privada de los servicios urbanos dentro de su área. Además, porque ofrecen a sus residentes una serie de servicios como seguridad, recolección de residuos, áreas verdes, alumbrado, etc. (Martín, 2006). Este modelo habitacional recibe diversas denominaciones según variaciones en cuanto a sus características y los sitios en donde se desarrollan. Por ejemplo, en Río de Janeiro se les nombra guetos de lujo, o bien, enclaves fortificados (Caldeira, 1999). En Estados Unidos por gated community, que no sólo se refieren a un barrio con delimitación política, sino con un significado de comunidad ya que incluye el establecimiento de reglamentos internos. Se distinguen varias categorias, como los country clubs y resorts, en la franja de contacto urbano-rural, con equipamiento de esparcimientos para viviendas secundarias y/o principal.

En México es común el uso del concepto fraccionamientos, conjuntos o desarrollos cerrados, los cuales varían según las localidades en que se presenten (Cabrales 2001). En algunas ciudades latinoamericanas se observan las grandes unidades o ciudades valladas, también llamadas ciudades satélite, que cuentan con una gran cantidad de servicios de comercio, cultura, esparcimiento, salud, etc. En general, estas urbanizaciones se ubican aisladas del espacio público común, en contextos jurídicos propios y distinguiéndose por rasgos comunes basados en el carácter privado y autogobernable de su organización (Véase tabla 1). 
Tabla 1. Tipología y características de desarrollos de viviendas en el área metropolitana de Santiago de Chile (2003)

\begin{tabular}{|l|l|}
\hline \multicolumn{1}{|c|}{ Tipología } & \multicolumn{1}{c|}{ Características } \\
\hline $\begin{array}{l}\text { Viviendas } \\
\text { unifamiliares en } \\
\text { copropiedad }\end{array}$ & $\begin{array}{l}\text { Perímetro cerrado, con acceso controlado y vigilancia permanente. Va de pocas viviendas, las que } \\
\text { en algunos casos no tienen vigilancia, hasta cerca de un centenar. Los de menor tamaño se han } \\
\text { construido muchas veces en el interior del área urbana, mientras que los de mayor tamaño se } \\
\text { ubican en la periferia de la ciudad. En general se organizan bajo el régimen de copropiedad. }\end{array}$ \\
\hline $\begin{array}{l}\text { Urbanizaciones } \\
\text { cerradas }\end{array}$ & $\begin{array}{l}\text { Corresponden a conjuntos de viviendas unifamiliares o multifamiliares de más de 100 viviendas, con } \\
\text { perímetro cerrado y accesos controlados. En la mayoria de las ocasiones no se encuentran amparados en la } \\
\text { normativa de copropiedad y han logrado legalidad a partir de la aplicación de las normas locales de cierre de } \\
\text { calles y pasajes. }\end{array}$ \\
\hline $\begin{array}{l}\text { Ciudades valladas o } \\
\text { ciudades satélite }\end{array}$ & $\begin{array}{l}\text { Son grandes proyectos inmobiliarios construidos por etapas y en la periferia inmediata de las áreas } \\
\text { metropolitanas. Principalmente están construidos por viviendas unifamiliares y multifamiliares. En su diseño } \\
\text { se considera una amplia gama de equipamientos y servicios, que dan autonomía a estos asentamientos } \\
\text { respecto del entorno urbano donde se localizan. }\end{array}$ \\
\hline $\begin{array}{l}\text { Edificio(s) de } \\
\text { departamentos }\end{array}$ & $\begin{array}{l}\text { Acceso controlado, vigilancia permanente o semi permanente y sistema de administración en régimen de } \\
\text { copropiedad }\end{array}$ \\
\hline Edificios de viviendas & $\begin{array}{l}\text { Edificios de departamento acogidos formalmente a la Ley de Copropiedad, en los cuales su aplicación es } \\
\text { básicamente para amparar la constricción en altura de distintas viviendas, no teniendo en la mayoría de los } \\
\text { casos cierres, vigilancia permanente ni acceso controlado. Estos conjuntos siguen el patrón de localización } \\
\text { tradicional de la vivienda social, en la periferia y en suelos con bajo valor. }\end{array}$ \\
\hline
\end{tabular}

Fuente: Modificado de Hidalgo, Álvarez y Salazar (2003).

Como se ha venido mencionando líneas arriba, el surgimiento de los desarrollos habitacionales cerrados corresponde a procesos donde una serie de cambios, posteriores a la crisis del sistema "fordista", se han venido produciendo; en particular desde mediados del siglo pasado. A éstos se les ha relacionado con la influencia de la globalización, vislumbrados desde enfoques multidisciplinarios. Las transformaciones en la organización del espacio urbano, a partir de los cambios sociales y económicos señalados, son evidentes en la estructura y función de los espacios periurbanos. Por ejemplo, en la creación de nuevas centralidades y con la formación de nuevos núcleos residenciales, los que, en su mayoría ofrecen servicios y funciones que habian sido propias del centro tradicional.

En un principio, la localización de estos núcleos se desarrolló de manera aislada en la franja suburbana; en parte como producto del abandono del centro como zona residencial por aquellos grupos de población con alto poder adquisitivo. Pero también, por el proceso de segregación socio residencial de grupos con ingresos menores, o de ciertas etnias que se mantenian en zonas alejadas carentes de servicios e infraestructura. Ante el crecimiento desmesurado de las grandes ciudades, la demanda de vivienda por clases sociales de diferentes rangos de ingreso ha estimulado la oferta de conjuntos masivos de vivienda y de costos accesibles para esos grupos.

Al intensificarse los fenómenos de competitividad económica y espacial, los agentes inmobiliarios promovieron el desarrollo de enclaves de viviendas con un diseño homogéneo y de tamaño reducido, acompañados por lo general de construcciones de centros de consumo con diversión y comercio que en un principio estaban dirigidos a las élites transnacionales. Fenómeno que conlleva a la manifestación territorial de las ciudades divididas y fragmentadas (Friedman y Goetz, 1982). Con el surgimiento de esos nuevos núcleos residenciales y de consumo, en Estados Unidos se creó un nuevo concepto del espacio público, el cual es explotado y controlado por el capital privado. Los estudios de la escuela de modelos concéntricos residenciales de Los Ángeles que dieron paso a enfoques sobre las plazas que tenian una función integradora del espacio público y que cambiaron los conceptos de mercadeo a través de los llamados "malls", pasando a ser centros de consumo exclusivo (Low, 2000).

En este sentido varios autores norteamericanos (Dear, 1988; Soja, 1989; Davis, 1990) realizaron estudios sobre el "urbanismo postmoderno" en la ciudad de Los Ángeles. Fueron ellos los primeros investigadores que aportaron análisis formales sobre la proliferación de los conjuntos habitacionales cerrados. Estos autores sostienen que el modelo de desarrollo neoliberal y la excesiva privatización de los servicios públicos en los años ochenta, se relaciona con el empobrecimiento de los grupos de menores ingresos y con el aumento en los niveles de criminalidad y violencia. Esto habría conducido a la expansión de los conjuntos residenciales cerrados, asociada a una demanda de protección por parte de los grupos de élite social; especialmente hacia los primeros años del siglo XXI. Se le vincula con los atentados del año 2001 en la ciudad de Nueva York.

En algunos paises, los agentes inmobiliarios involucrados en el mercado y propietarios, tanto del suelo como de la vivienda, fueron quienes jugaron un papel preponderante en este proceso. Sin embargo, la participación del gobierno cobró im- 
portancia con la llamada vivienda de interés social, bajo la cual el mismo gobierno actúa como promotor del desarrollo urbano que fomenta la construcción de viviendas para grupos de clase media y media baja y, además, funge como agente regulador en cuanto al uso del suelo (Hidalgo, Álvarez y Salazar, 2003).

No obstante, algunos de los nuevos escenarios económicos, principalmente en las ciudades postmodernas, se relacionan con la liberalización de las fuerzas del mercado del suelo bajo la cual predomina el interés del capital. Al mismo tiempo que se privatizan los servicios y el uso del espacio público, ha habido una disminución de la intervención pública directa. Ante este fenómeno, la inversión gubernamental en vivienda e infraestructura de servicios y equipamiento público se ha visto limitada y se hace presente la desactivación de las instituciones. Este proceso da como resultado nuevas instancias de poder, equivalente a una transferencia de la gestión del desarrollo urbano a los inversores privados (Curtit, 2003). En algunas aproximaciones de estudio se ha visto que las urbanizaciones cerradas no son privativas de los grupos de clases altas y medias, sino que también se da en los alrededores de los barrios marginales. Lo que prueba que el fenómeno no es una forma habitacional exclusiva sólo de los beneficiados con la transformación y globalización de la economía (Sabatini, 2000 y 2003).

\section{EL PERIURBANO RESIDENCIAL EN TIJUANA Y LOS DESARROLLOS HABITACIONALES CERRADOS}

\subsection{Tijuana: una ciudad en constante expansión}

El municipio de Tijuana es el segundo más pequeño del estado de Baja California. Sus $1.239 .49 \mathrm{~km}^{2}$ representan sólo el 1.7\% del área estatal y su densidad de población (1.258 hab/ $\left.\mathrm{km}^{2}\right)$ contrasta con la de los demás municipios (Tabla 2). Este territorio se localiza en el extremo noroeste de la franja fronteriza de México, compartiendo frontera al norte con el condado de San Diego, California, en Estados Unidos, al sur con el municipio de Playas de Rosarito, al este con la zona de conurbación TijuanaTecate y al oeste con el Océano Pacífico (Véase figura 1).

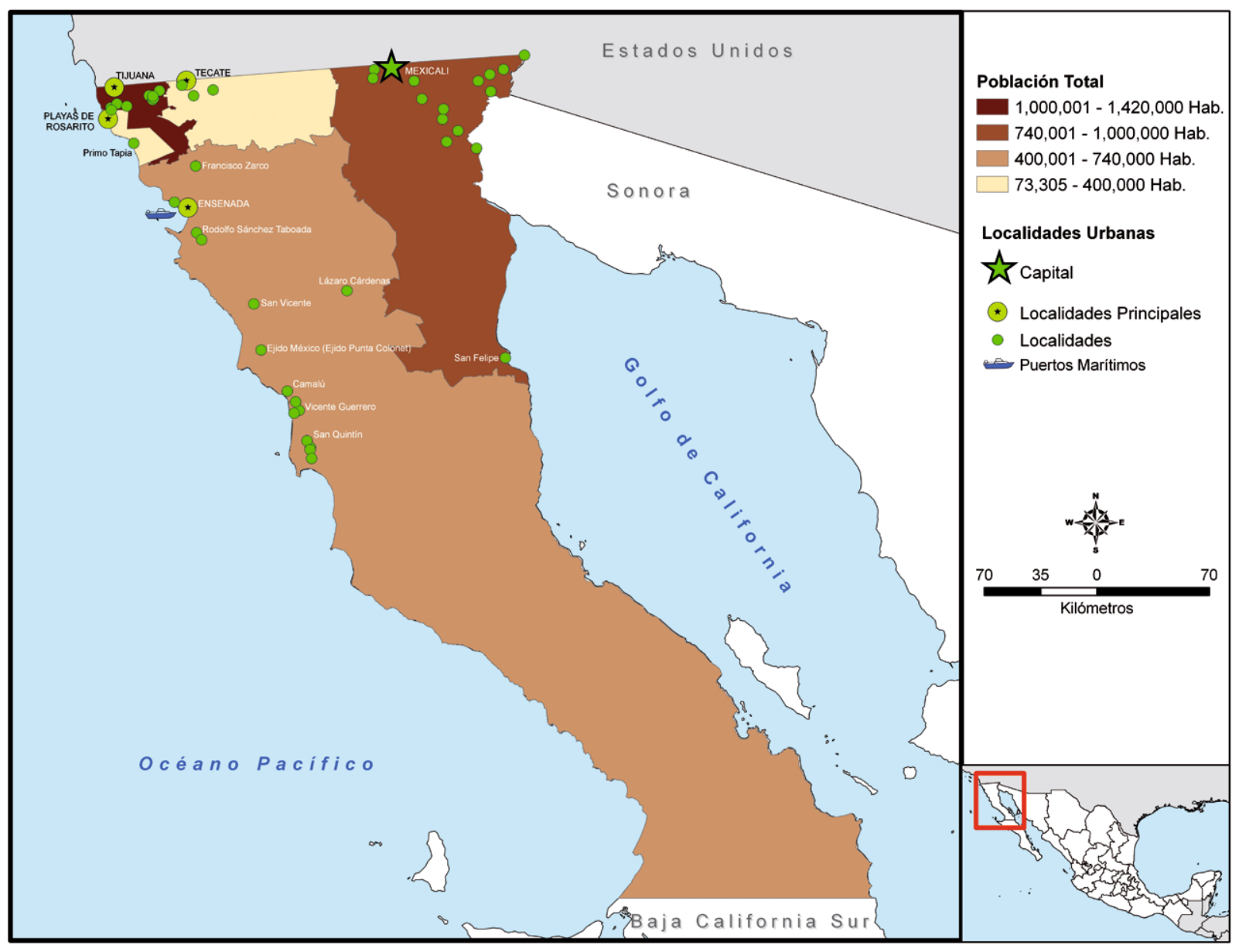

A Figura 1. Mapa de Baja California por municipios y principales localidades.

FuENTE: Elaboración propia en base a información de INEGI, Censo General de Población y Vivienda. 2000. Sistema para la Consulta de Información Central (SINCE). 
Tabla 2. Población total 1990-2010 por municipio y proporción estatal en Baja California

\begin{tabular}{|l|c|c|c|c|c|c|c|c|}
\hline \multirow{2}{*}{ Municipio } & \multicolumn{2}{|c|}{1990} & \multicolumn{2}{c|}{2000} & \multicolumn{3}{c|}{2010} \\
\cline { 2 - 9 } & Población & Porcentaje & Población & Porcentaje & Población & $\begin{array}{c}\text { Porcentaje } \\
\begin{array}{c}\text { Superficie } \\
\mathrm{km}^{2}\end{array}\end{array} \begin{array}{c}\text { Densidad } \\
\left.\mathrm{hab}^{\mathrm{k}} \mathrm{km}^{2}\right)\end{array}$ \\
\hline Ensenada & 255.776 & $15,7 \%$ & 369.573 & $14,9 \%$ & 466.814 & $14,8 \%$ & $52.510,7$ & 8,89 \\
\hline Mexicali & 589.650 & $36,2 \%$ & 764.902 & $30,7 \%$ & 936.826 & $29,7 \%$ & $13.935,6$ & 67,23 \\
\hline Tecate & 51.197 & $3,1 \%$ & 77.444 & $3,1 \%$ & 101.079 & $3,2 \%$ & $3.578,5$ & 28,25 \\
\hline Tijuana & 733.893 & $45,0 \%$ & 1.212 .232 & $48,7 \%$ & 1.559 .683 & $49,4 \%$ & $1.239,5$ & $1.258,33$ \\
\hline $\begin{array}{l}\text { Playas de } \\
\text { Rosarito }\end{array}$ & $\mathrm{n} / \mathrm{a}$ & $\mathrm{n} / \mathrm{a}$ & 63.549 & $2,6 \%$ & 90.668 & $2,9 \%$ & 513,3 & 176,63 \\
\hline $\begin{array}{l}\text { Baja } \\
\text { California }\end{array}$ & 1.630 .516 & $100 \%$ & 2.487 .700 & $100 \%$ & 3.155 .070 & $100 \%$ & $71.778,00$ & 43,96 \\
\hline
\end{tabular}

Fuente: Censos generales de población y vivienda 1990, 2000, 2010 y II Conteo de población y vivienda 2005, INEGI.

El desarrollo socioeconómico de la ciudad está relacionado con diversos acontecimientos históricos. Es, además, producto de su estratégica cercanía con el estado norteamericano de California. Esta situación fronteriza la ha convertido en un importante centro de atracción de capital y de población. Actualmente la concentración de la población urbana en el estado de Baja California es del 85\%, distribuida en sólo 10 localidades, de las cuales Tijuana es la de mayor población. Del total de la población estatal (3.155.070), Tijuana concentra el 49\%, con 1.559 .683 habitantes ${ }^{4}$, siendo su cabecera la única localidad del estado que supera el miIlón de habitantes (Véase tabla 2).

En las etapas de mayor crecimiento demográfico, entre 1950 y 1960, la ciudad llegó a tener tasas de incremento anual por encima del 9\%, disminuyendo hacia el 2000, con el 4,1\%, para llegar en el 2010 al 2\%. En este proceso el componente migratorio ha sido muy importante, en gran parte debido a la atracción que representa la frontera con Estados Unidos ${ }^{5}$. Un importante indicador socioeconómico es la población económicamente activa (PEA), correspondiente a aquella población mayor de 12 años y que realiza alguna actividad productiva, la cual corresponde al 59,3\% del total de ese grupo.

En el tema de la vivienda la problemática en la región no solo se centra en la demanda cuantitativa, sino también en las condiciones generales de habitabilidad; como puede ser la dimensión de la superficie construida y otros factores que caracterizarian a una vivienda adecuada ${ }^{6}$. En este sentido, algunas de las condiciones, como los servicios en la vivienda y las características de los materiales de construcción, en general, resultan bastante aceptables (Véase tabla 3). En cuanto a la demanda, en la ciudad se requieren alrededor de 21.392 viviendas, de las cuales el 70\% corresponde a vivienda económica y tradicional. Estaría dirigida al grupo que gana de entre dos a cuatro salarios mínimos, incluso hasta los de 4 a 7 veces dicho salario ${ }^{7}$. El 60\% de la población gana más de dos salarios mínimos, y como promedio, tiene un ingreso mensual de $6.800,00$ pesos. No obstante, esta situación, y ante la dinámica socioeconómica que presenta Tijuana, las instituciones -tanto públicas como privadas- ofertan en su mayoría desarrollos habitacionales con viviendas de interés social del tipo económica social, cuya superficie de construcción va de 31 a 45 metros cuadrados. La superficie corresponde a los mínimos establecidos en la Ley Estatal de Edificaciones de 1994, reformada en 2008. Está destinada a la población de más bajos ingresos y cuya calidad de vida se ha visto afectada.

En las figuras 2, 3 y 4 se presentan fotografias con ejemplos de viviendas del tipo económica social de tamaño reducido. Construyen los desarrollos habitacionales de miles de viviendas.

(4) INEGI, XIII Censo General de Población y Vivienda 2010. México.

(5) Según el Censo de 2010 la población no nativa en la ciudad era del 48.3\%.

(6) De acuerdo a la Ley Federal de Vivienda se aplicaba el concepto de vivienda digna y decorosa cuando se trata de las necesidades de vivienda, pero este concepto se refiere a la seguridad jurídica, por lo que en organismos internacionales es usado el término de vivienda adecuada el cual significa más que un techo; también significa disponer de un lugar privado, espacio suficiente, accesibilidad física, seguridad adecuada, seguridad de tenencia, y durabilidad estructural, además de ventilación suficiente, una infraestructura básica de servicios, factores apropiados de calidad ambiental y relación con la salud, así como un desplazamiento adecuado y con acceso al trabajo y a los servicios; todo ello a un costo razonable. Conferencia de las Naciones Unidas sobre los Asentamientos Humanos (Habitat II), Programa de Habitat, 1996.

(7) Datos del Plan Sectorial de Vivienda del Estado de Baja California 2009-2013. 

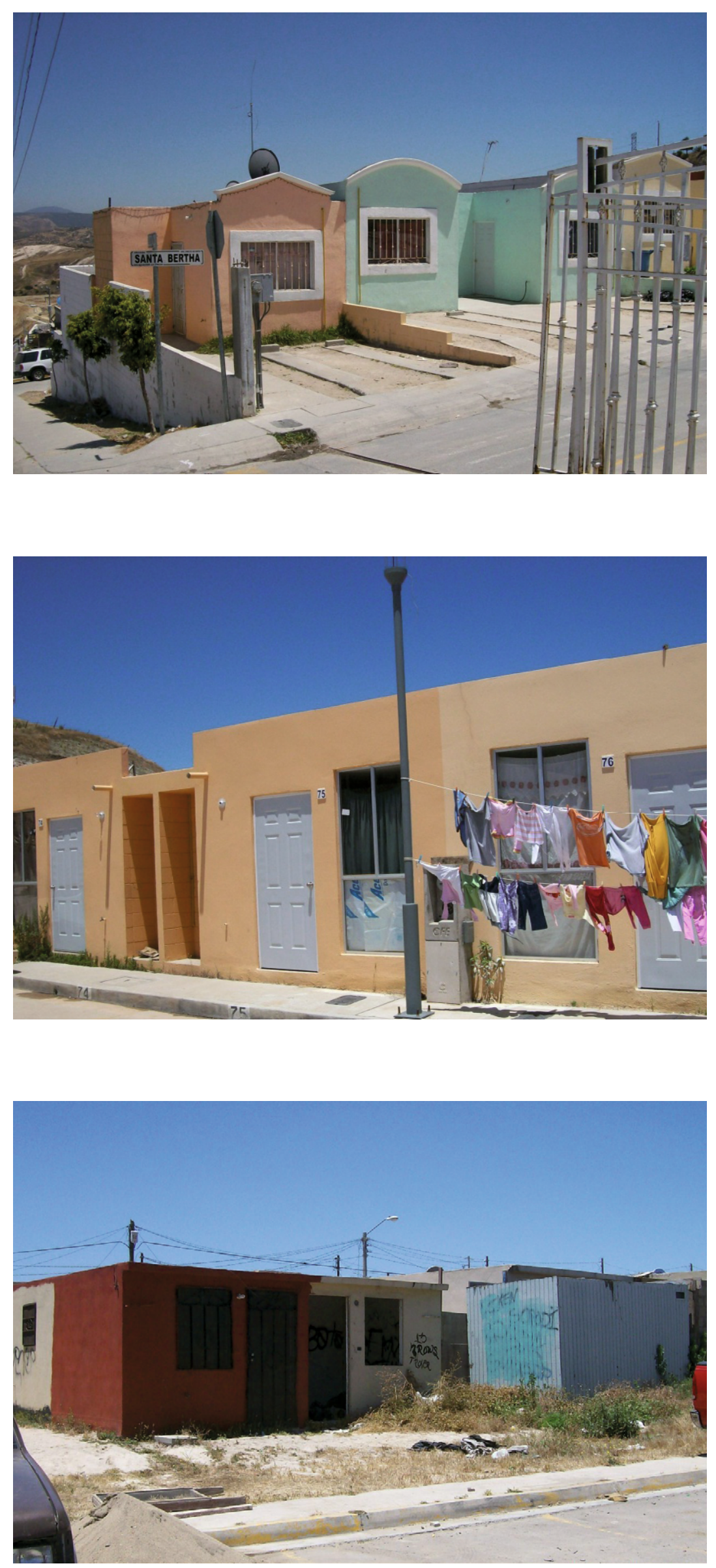

4 Figura 2. Fraccionamiento San Martín (Zona Sur).

4 Figura 3. Hacienda Las Delicias (Zona Sur).

4 Figura 4. Urbi Villas del Prado (Zona Sur). 
Tabla 3. Viviendas particulares según principales características por municipio en Baja California, 2010

\begin{tabular}{|c|c|c|c|c|c|c|c|c|c|c|c|c|c|}
\hline \multirow[b]{2}{*}{ Municipio } & \multirow[b]{2}{*}{$\begin{array}{l}\text { Viviendas } \\
\text { particulares }\end{array}$} & \multirow[b]{2}{*}{$\%$} & \multicolumn{4}{|c|}{ Condición de habitación } & \multirow[b]{2}{*}{$\begin{array}{l}\text { Promedio } \\
\text { de } \\
\text { cuartos } \\
\text { por } \\
\text { vivienda }\end{array}$} & \multirow{2}{*}{$\begin{array}{c}\% \text { de } \\
\text { ocupantes } \\
\text { en } \\
\text { viviendas } \\
\text { que } \\
\text { disponen } \\
\text { de agua } \\
\text { entubada }\end{array}$} & \multirow[b]{2}{*}{$\begin{array}{c}\% \text { de } \\
\text { ocupantes } \\
\text { en } \\
\text { viviendas } \\
\text { que } \\
\text { disponen } \\
\text { de energía } \\
\text { eléctrica }\end{array}$} & \multirow{2}{*}{$\begin{array}{c}\% \text { de } \\
\text { ocupantes } \\
\text { en } \\
\text { viviendas } \\
\text { que } \\
\text { disponen } \\
\text { de } \\
\text { excusado y } \\
\text { drenaje }\end{array}$} & \multicolumn{3}{|c|}{ Viviendas con material en piso* } \\
\hline & & & Habitadas & $\%$ & Deshabitadas & $\%$ & & & & & Tierra & $\begin{array}{c}\text { Cemento, } \\
\text { madera } \\
\text { mosaico } \\
\text { u otro } \\
\text { recubrimiento }\end{array}$ & $\%$ \\
\hline Ensenada & 168.815 & $14,8 \%$ & 129.558 & $14,9 \%$ & 25.621 & $11,9 \%$ & 3,7 & 90,6 & 97,1 & 81,0 & 4.533 & 121.262 & $14,9 \%$ \\
\hline Mexicali & 346.940 & $30,4 \%$ & 265.730 & $30,5 \%$ & 64.419 & $30,0 \%$ & 3,9 & 98,0 & 98,9 & 91,8 & 5.877 & 251.270 & $30,4 \%$ \\
\hline Tecate & 36.002 & $3,2 \%$ & 26.227 & $3,0 \%$ & 5.982 & $2,8 \%$ & 3,8 & 89,0 & 96,6 & 92,5 & 852 & 24.482 & $3,0 \%$ \\
\hline Tijuana & 553.115 & $48,4 \%$ & 423.741 & $48,7 \%$ & 111.482 & $51,9 \%$ & 3,8 & 97,3 & 98,9 & 96,7 & 16.147 & 400.108 & $49,1 \%$ \\
\hline $\begin{array}{c}\text { Playas de } \\
\text { Rosarito }\end{array}$ & 37.786 & $3,3 \%$ & 25.054 & $2,9 \%$ & 7.201 & $3,4 \%$ & 3,6 & 84,0 & 96,2 & 92,4 & 803 & 21.758 & $2,7 \%$ \\
\hline $\begin{array}{c}\text { Baja } \\
\text { California }\end{array}$ & 1.142 .658 & $100 \%$ & 870.310 & $100 \%$ & 214.705 & $100 \%$ & 3,8 & 95,9 & 98,5 & 92,7 & 28.212 & 818.880 & $100 \%$ \\
\hline
\end{tabular}

Fuente: Censo Generales de Población y Vivienda 2010. INEGI.

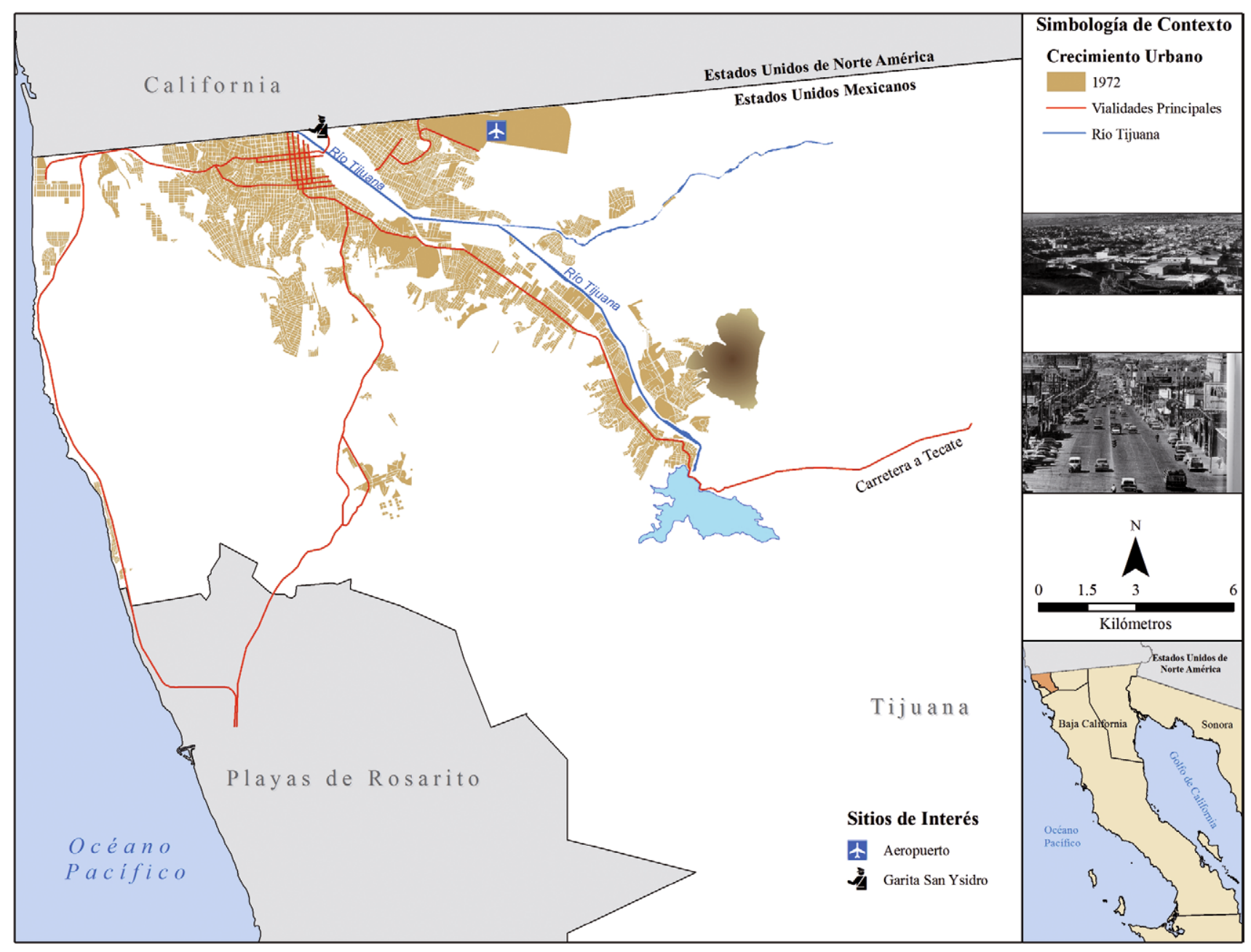

$\Delta$ Figura 5. Mapa del área de crecimiento urbano en Tijuana, B.C. (1972).

FuENTE: Elaborado en base al Sistema para la Consulta de Información Central (SINCE) y Censo de Población y Vivienda, INEGI (2000). 


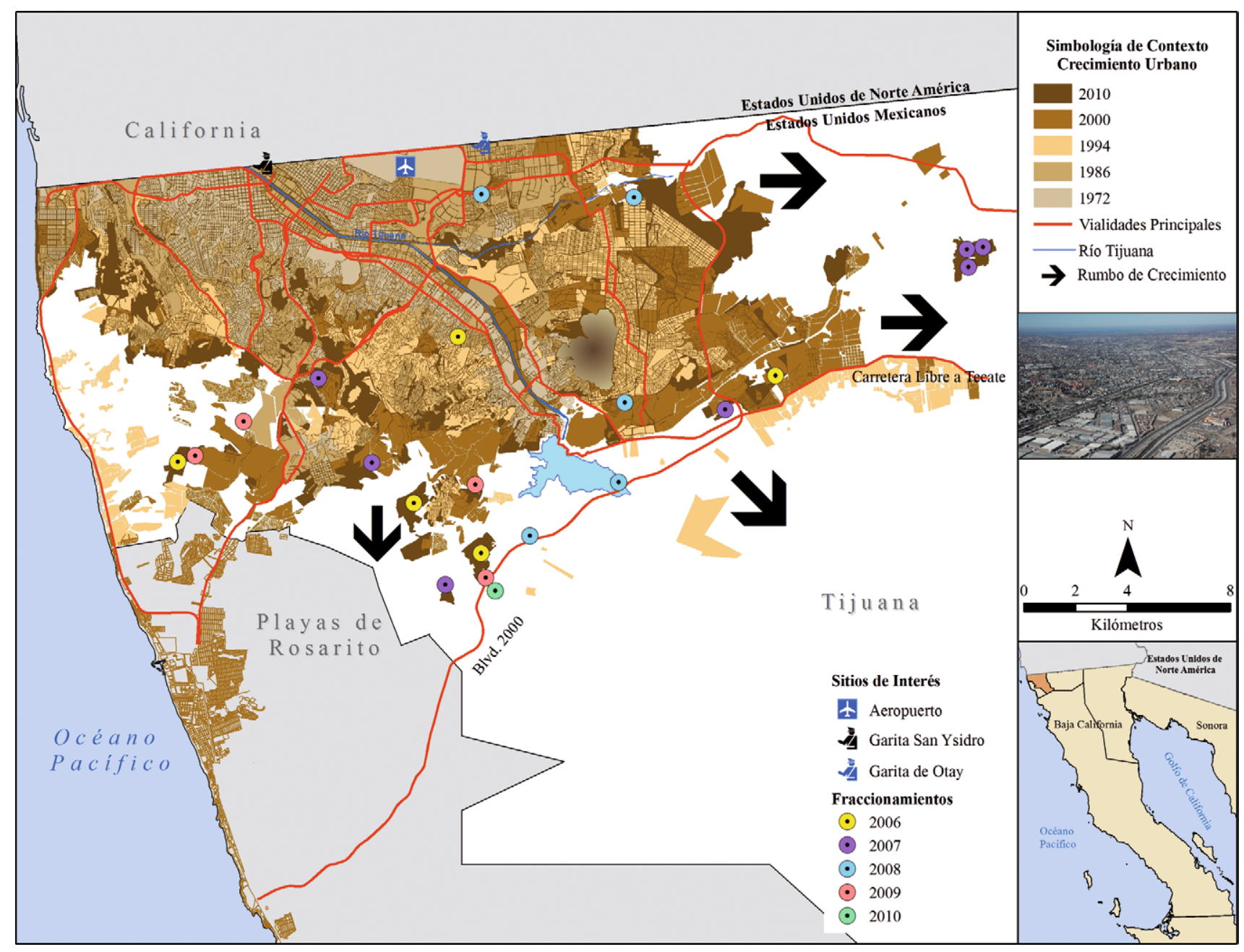

\ Figura 6. Mapa del área de crecimiento urbano en Tijuana, B.C. (1972-2010).

FUENTE: Elaborado en base al Sistema para la Consulta de Información Central (SINCE) y Censo de Población y Vivienda, INEGI (2010).

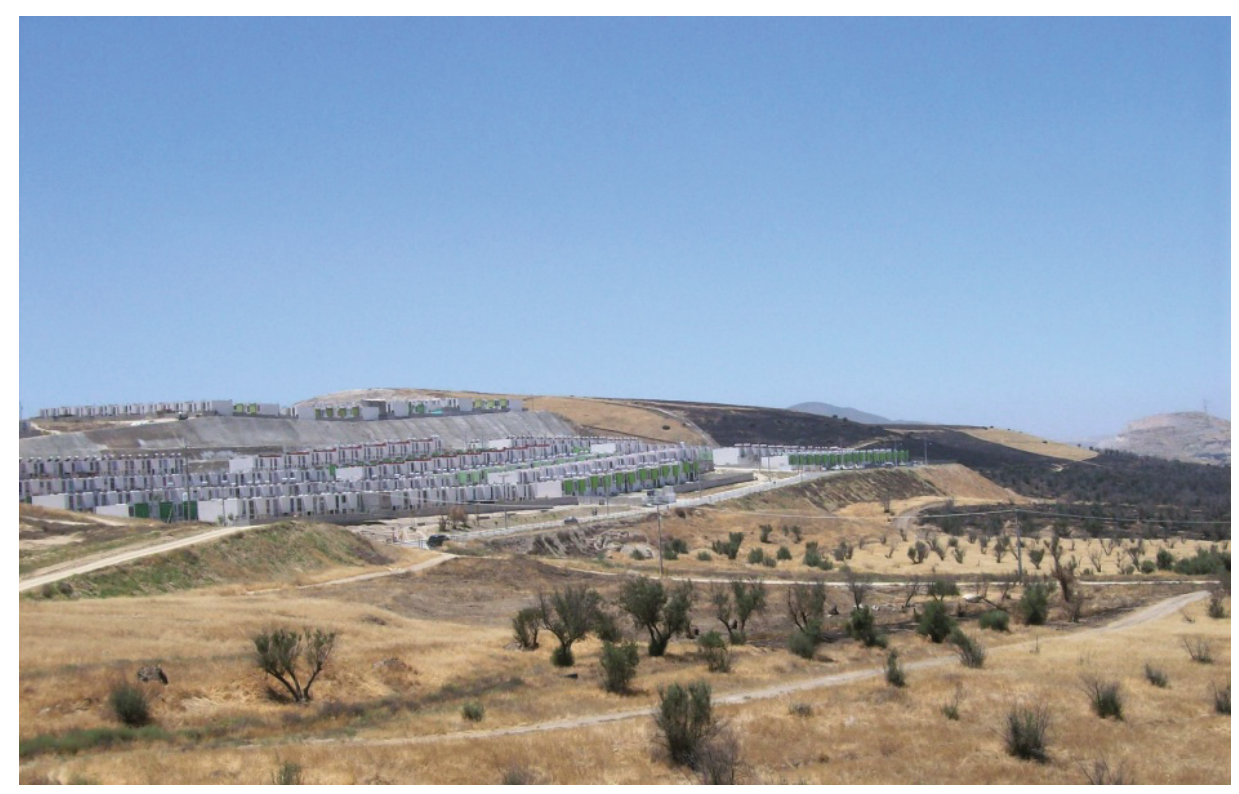

\ FIgURA 7. Paisaje de crecimiento habitacional periurbano. Paseos del Vergel (Zona Sur). 


\subsection{Crecimiento de la mancha urbana y el espacio habitable}

Desde sus inicios, a principios del siglo pasado, la ciudad de Tijuana fue emplazada de manera concéntrica alrededor del centro tradicional, contiguo a la línea fronteriza con Estados Unidos. El entorno del paisaje físico es de relieve accidentado, con sistemas de lomerios, cañones, mesetas bajas y algunas Ilanuras hacia el sureste y el este, en donde da inicio la más importante corriente hidrográfica de la región. El río Tijuana, que atraviesa la ciudad del sureste al noroeste, desemboca en las costas de Estados Unidos. Para 1950 la superficie de la ciudad era de 1.686 hectáreas (IMPLAN, 2009), presentándose un crecimiento residencial en las áreas aptas para la urbanización. En particular en los alrededores de la zona central, así como hacia el este y el noreste, donde una extensa meseta baja permitió la expansión de diversos usos de suelo; tanto industrial como de servicios y para áreas verdes (Véase mapa en la figura 5).

Así, ante el auge migratorio y el impulso de actividades productivas, la demanda de vivienda aumentó de manera acelerada. Esto generó un proceso de regularización de predios en litigio o de origen agrícola, los cuales pasarian a formar de las primeras zonas residenciales periféricas a lo largo de las vialidades y riberas del rio Tijuana; sobre todo siguiendo el rumbo hacia los municipios más cercanos, como Tecate. Durante los años sesenta y setenta estos procesos dieron lugar a importantes desequilibrios entre la ocupación del suelo y la capacidad del gobierno local para introducir los servicios necesarios e infraestructura. En las siguientes décadas la mancha urbana creció rápidamente, y en 1994 ya cubría alrededor de 19.500 hectáreas, casi 12 veces la que tenía en 1950. Pero la ocupación era irregular y dispersa, tomando en cuenta la inaccesible configuración topográfica ${ }^{8}$ y el desfase en la adecuación de los terrenos para su urbanización. Esta condición marcó las diferentes direcciones del crecimiento urbano de la ciudad (Véase mapa en la figura 6). En la figura 7 se aprecia la vista de un paisaje de expansión habitacional periurbana.

En los últimos años el espacio habitable comprende una superficie de aproximadamente de 34.462 hectáreas, cuya configuración se encuentra estructurada por un Centro Urbano consolidado compuesto por dos núcleos, el Centro Tradicional y la Zona Río Tijuana, además de 19 subcentros y 16 corredores urbanos. Sin duda, el Centro Urbano sigue siendo una zona de alta concentración de funciones comer- ciales, turisticas y administrativas. Junto con la Zona Río Tijuana representan las zonas de mayor accesibilidad y valor económico. Tanto por la confluencia de la mayoria de las líneas de transporte, como por la alta competencia entre los usos de suelo y con una constante renovación urbanística. Lo que continuamente desplaza a residentes de bajo nivel de renta a otras áreas de la ciudad, como son las periferias ${ }^{9}$.

El conjunto de la superficie en usos residenciales se compone de colonias populares, fraccionamientos o desarrollos habitacionales cerrados y abiertos, así como asentamientos irregulares con viviendas de diferentes calidades de materiales y construcción. Esta superficie es de aproximadamente 11.244 hectáreas, que representa el $32,7 \%$ del total y que, junto con la de baldío (27\%), constituye la mayor parte del área urbana y periurbana urbanizada. La mayor parte del uso habitacional es de vivienda multifamiliar (72\%), que pueden ser viviendas unitarias de tipo horizontal o vertical, pero organizado por el régimen de condominio o copropiedad; en su mayoría son financiadas con interés social. La vivienda unifamiliar de interés medio es del 36\% y el social progresivo de 35\% (Véase tabla 4).

Tabla 4. Acciones de urbanización para el uso habitacional del suelo (2009). Tijuana, B.C.

\begin{tabular}{|c|c|c|}
\hline \multirow{2}{*}{ Usos de Suelo } & \multirow{2}{*}{ Modalidad } & Superficie \\
\hline & & (has) \\
\hline \multirow{6}{*}{$\begin{array}{l}\text { Habitacional } \\
\text { Unifamiliar }\end{array}$} & Interés Medio & $108.808,2$ \\
\hline & Social Progresivo & $99.979,3$ \\
\hline & Residencial & $56.850,3$ \\
\hline & Interés Social & 31.441 .5 \\
\hline & Habitacional & $1.328,4$ \\
\hline & Subtotal & $298.407,7$ \\
\hline \multirow{3}{*}{$\begin{array}{l}\text { Habitacional } \\
\text { Multifamiliar }\end{array}$} & Interés Social & $1.193 .097,4$ \\
\hline & Interés Medio & $110.162,6$ \\
\hline & Subtotal & $1.303 .260,0$ \\
\hline \multirow{2}{*}{$\begin{array}{l}\text { Habitacional } \\
\text { Unifamiliar y } \\
\text { Multifamiliar }\end{array}$} & Interés Social & $175.249,6$ \\
\hline & Subtotal & $175.249,6$ \\
\hline Industrial & Subtotal & $25.865,5$ \\
\hline \multicolumn{2}{|r|}{ Total } & $1.802 .782,8$ \\
\hline
\end{tabular}

Fuente: Instituto Municipal de Planeación (IMPLAN), Tijuana, 2009.

(8) Según cálculos, el 33\% del área estaba ocupada por barrancos, cañones, cerros y lomeríos (SAHOPE, 1991).

(9) Bajo la normatividad del Programa de Desarrollo Urbano del Centro de Población de Tijuana, B.C. (2009-2030) para el periodo $2002-2009$ la superficie ocupada que se incrementó, principalmente en las áreas periurbanas, fue de 13708 hectáreas, de las cuales se tenía contemplado el incremento de zonas programadas para distintos usos y plazos, como áreas de preservación y de reserva territorial. De esta superficie el $57 \%$ (7 765 hectáreas) fue destinado a acciones formales de urbanización como uso habitacional, comercial e industrial. 


\subsection{Conformación de los desarrollos habitacionales cerrados en Tijuana}

En el proceso de conformación del espacio residencial periurbano en Tijuana, en especial a mediados del siglo pasado y bajo la influencia de los efectos de la globalización, la dinámica socioeconómica de la ciudad condujo a una alta demanda del espacio urbanizado. En ese tiempo se presentaron problemáticas relacionadas con la poca disponibilidad de suelo apto para desarrollos habitacionales, pero también con la escasa gestión urbana para solucionar el estado legal de gran parte de predios irregulares, así como de la introducción de los elementos básicos de urbanización ${ }^{10}$. Esta situación propició la proliferación de invasiones, asentamientos ilegales y de ocupaciones en zonas de alto riesgo para la construcción urbana. Sin embargo, ante el crecimiento de la demanda de espacio habitable y con la aplicación de una política urbana que favoreciera la planificación, la construcción de unidades habitacionales de distintas caracteristicas se vio beneficiada. Esto permitió amortiguar los efectos en el déficit de vivienda de la ciudad.

A finales de los años setenta y principios de los ochenta se construyeron los primeros proyectos de vivienda del tipo multifamiliar, combinados con proyectos unifamiliares y de inversión estatal. Estos proyectos ya perfilaban el concepto de cercamiento y seguridad en los accesos. También se realizaron proyectos dirigidos a un mercado integrado por extranjeros, quienes encontraban mejores precios de este lado de la frontera. Esos proyectos están ubicados principalmente a lo largo de la costa occidental, como los de tipo club resort. De la misma manera, a principios de los años noventa fueron construidos conjuntos residenciales de pocas viviendas pero amplias, con accesos controlados, seguridad propia y de carácter exclusivo. Pero estaban dirigidos a los estratos de alto poder adquisitivo y con una importante vista sobre el paisaje natural. Por ejemplo, los conjuntos Residencial Agua Caliente, Residencial Puerta de Hierro y Fraccionamiento Chapultepec.

En contraste, durante la segunda mitad de los años noventa comenzó a observarse una mayor cantidad de desarrollos habitacionales populares. Se trataba de cientos de viviendas de tamaño reducido y de dudosa calidad. Por ejemplo, los conjuntos Hacienda Las Fuentes y Misión de las Californias I, II, III, ubicados en las periferias hacia el este y sureste de la ciudad. En total fueron alrededor de 32 los desarrollos cerrados que se autorizaron en esa década. El establecimiento de una regulación que ordenara la copropiedad que caracterizó a estos de- sarrollos marcó directrices que coadyuvarían a su proliferación, ya que el tipo de régimen en condominio favorece las condiciones de convivencia organizada. En la región se tiene la Ley sobre el Régimen de Propiedad en Condominio de Inmuebles para el estado de Baja California, promulgada en el $2004{ }^{11}$.

Ahora bien, a partir de los primeros años del nuevo siglo el espacio disponible para uso habitacional en las zonas de crecimiento más próximas a las zonas centrales disminuyó notablemente, mientras que el número de proyectos aumentaba. En tres años se autorizaron 22 desarrollos, de los cuales el $68 \%$ fueron del tipo multifamiliar y en la mayoria de los casos de interés social; solo 5 fueron de interés medio. La mayor cantidad de estos desarrollos se construyeron en el 2004, con 15 proyectos del rango de cientos de viviendas cada uno, y de éstos, el 87\% fueron del tipo multifamiliar y de interés social. Entre 2005 y 2007 fueron autorizados 21 del tipo multifamiliar y de interés social. Es entonces cuando comienza a observarse el incremento en el número de viviendas por proyecto. Por ejemplo, en los desarrollos Villa Residencial, Santa Fe y sus secciones. El caso de Urbi Villa del Prado, del 2005, representa el primero de los grandes conjuntos con 6.000 viviendas. Después, en 2006, y en ese mismo desarrollo, Urbi del Prado Segunda Sección, fueron autorizadas 7.578 viviendas. Solo en el año 2007 se ofertaron 25.829 viviendas en 7 desarrollos, y en 201018.727 viviendas en 5 desarrollos.

Durante los últimos años, la tendencia ha sido de una disminución en la cantidad de desarrollos, pero con la misma pauta de alto número de viviendas por cada desarrollo. Los cuales han sido ubicados en la franja periurbana más exterior de la ciudad. Gran parte de estos conjuntos están dirigidos a una población de ingresos bajo y medio-bajo. En su mayoría se trata de viviendas de tamaño reducido (31 a 45 metros cuadrados), con diseño uniforme y con baja calidad en los materiales, las que se denominan vivienda económica social.

En términos generales, estos desarrollos han sido construidos por empresas inmobiliarias privadas y financiados en su mayoría por instituciones públicas, como Infonavit y Fovissste, o través de la banca privada y con diferentes rangos de tasas de interés. En un principio fueron dirigidos a grupos de clases medias y altas, y en zonas accesibles, es decir, cercanas a las zonas centrales y con altos grados de urbanización. Pero como ha sucedido en la mayoría de las ciudades, la presencia de suelo de bajo costo y la condición de legalidad en zonas de crecimiento periurbano ha propiciado las grandes construcciones de vi-

$\left.{ }^{10}\right)$ Según algunos estudios, el 57\% de las viviendas ocupadas que existian en Tijuana para el año 2000, tuvieron un origen irregular, ya que se identificaron 166234 predios de ese tipo. Respecto al total de viviendas ocupadas que reportó el censo del mismo año, esa era la magnitud del problema (Alegria y Ordoñez, 2005).

(11) Esta ley establece en su artículo 3 que "cuando los diferentes departamentos, viviendas, casas o locales de un inmueble construidos en forma vertical, horizontal o mixta, susceptibles de aprovechamiento independiente, por tener salida propia a un elemento común de aquél, o a la vía pública, pertenecieran a distintos propietarios, cada uno de éstos tendría un derecho singular y exclusivo de propiedad sobre su departamento, vivienda, casa o local y, además un derecho de copropiedad sobre los elementos y partes comunes del inmueble, necesarios para su adecuado uso o disfrute". 


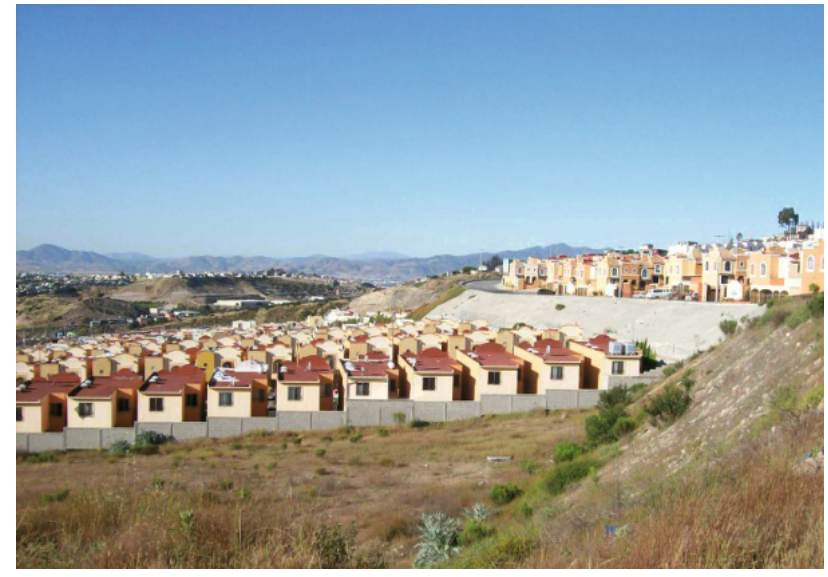

A Figura 8. Pórticos de San Antonio (Zona Suroeste).

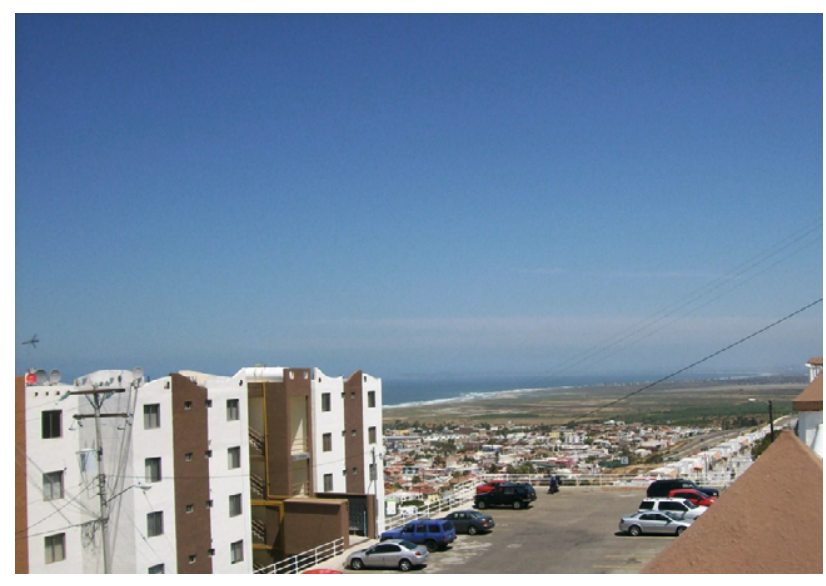

A Figura 9. Laderas del Mar (Zona Noroeste costera).

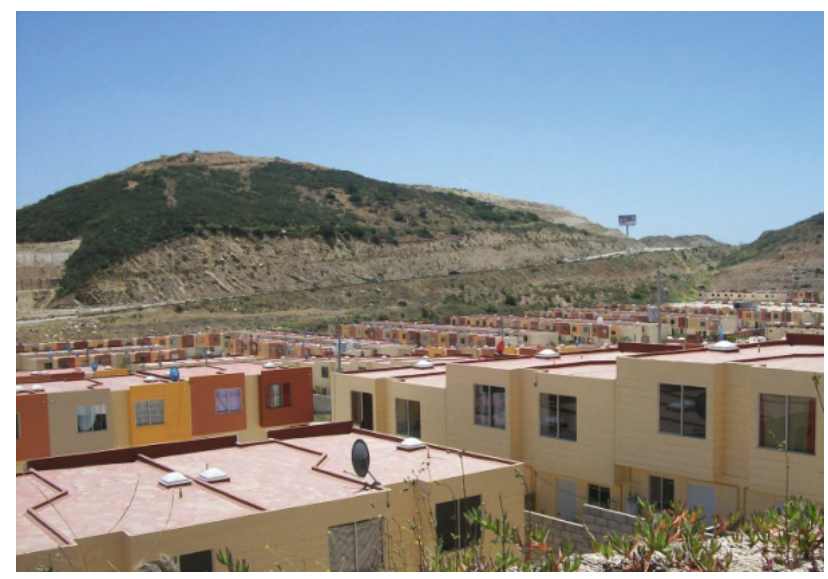

A Figura 10. Hacienda Las Delicias (Zona Sur). viendas en conjuntos aislados y la dispersión al interior de amplias extensiones deshabitadas. Gran parte de las empresas inmobiliarias forman parte del capital financiero, tanto nacional como internacional (Geo, Urbi, Ara, Frisa, Promocasa, Ruba, CYD, y otras). Las figuras 8,9 y 10 muestran fotografías de algunos de los desarrollos habitacionales más característicos en las áreas periurbanas.

\subsection{La distribución geográfica de los desarrollos habitacionales cerrados}

En la franja periurbana predomina un patrón de distribución residencial que, conforme aumenta la distancia en relación al centro de la ciudad, los costos por transporte se elevan. Sin embargo, otros elementos, como el precio del suelo tiende a disminuir. Por lo que para la industria constructora existen ventajas comparativas que estimulan la localización de núcleos habitacionales en zonas periurbanas distantes del centro urbano. Esta situación se mezcla con los usos rurales y de otra naturaleza, definiendo así las áreas rururbanas. Por lo común la localización residencial se concentra de manera sectorial a lo largo de las principales vías de comunicación, creando una forma de estrella. Como sucedió a principios de siglo en la estructura intraurbana de la mayoría de las ciudades (Zarate, 1991).

Como se ha venido mencionando, la distribución geográfica de los desarrollos habitacionales cerrados en el área periurbana de la ciudad, ha estado influenciada por una serie de condiciones. Como es el suelo abundante de estatus legal y bajo costo; el desarrollo de infraestructura, como vialidades y transporte público, aunque éste no es totalmente eficiente. La presencia de fuentes de empleo en parques industriales y centros comerciales, así como los atractivos ambientales, también representan condiciones que han impulsado este tipo de desarrollos. Sin embargo, la demanda de vivienda también contribuyó a que las agencias inmobiliarias ofertaran cada vez proyectos más grandes y cada vez más alejados de los centros laborales y de consumo.

Con la intención de facilitar el estudio del patrón de localización de los fraccionamientos y sus relaciones con otros recursos urbanos, se analizó la ubicación de estos por zonas geográficas. En la figura 11 se aprecia el mapa con la distribución general de los desarrollos por zonas, y en la que destacan los grupos que se han formado en torno al sistema periurbano de vialidades y que, en general, sigue las direcciones de crecimiento de la mancha urbana. En total se registraron 147 fraccionamientos con características diversas, que van desde el tipo multifamiliar y unifamiliar de interés social y medio, en copropiedad, hasta urbanizaciones cerradas de cientos y miles de viviendasubicadas en la franja periurbana exterior. 
La ciudad fue subdividida en ocho zonas geográficas, de las cuales la zona Suroeste es la que presenta el mayor número de desarrollos habitacionales (24\%), le sigue la zona Centro (19\%), para continuar con la Noroeste (12\%). Las otras zonas de expansión son la Este, la Sureste y la Sur, las cuales no presentan una alta concentración en el número de fraccionamientos, pero sí en la concentración de viviendas (Véase tabla 5). Además, estas zonas se relacionan con la planeación de áreas programadas para reserva habitacional y representan las rutas de expansión con más potencial para el crecimiento de la ciudad. Este proceso se intensificó a partir de la construcción de la vialidad Corredor 2000, el cual ha impulsado a las agencias inmobiliarias a desarrollar proyectos de gran cantidad de viviendas de interés social en esa parte de la ciudad (Véase figura 11 y tabla 5).

De las ocho zonas en que se dividió el área ocupada por los desarrollos cerrados, destacan aquellas con una localiza- ción en el periurbano exterior y que marcan las direcciones del crecimiento de la ciudad, tales como la zona Suroeste, la Sur, la Noreste, la del Este y la del Sureste. En el mapa de la figura 11y especificamente en la tabla 6 es posible observar la gran distancia a la que se encuentran los desarrollos respecto de los principales centros de actividades, así como la relación de su ubicación y expansión respecto de las principales vías de comunicación. Los centros de actividades se consideran como zonas de alta atracción de población y capital por satisfacer servicios como la interconexión de rutas de transporte público, centros de empleo y consumo, así como de servicios educativos, médicos, de gestión administrativa y de esparcimiento, entre otros. Algunos ejemplos de desarrollos o graccionamientos habitacionales en zonas periurbanas exteriores se muestran en las figuras $12,13,14$ y 15 . Se observan conjuntos de viviendas en contacto con usos rurales y otros desarrollos comunes en áreas periurbanas.

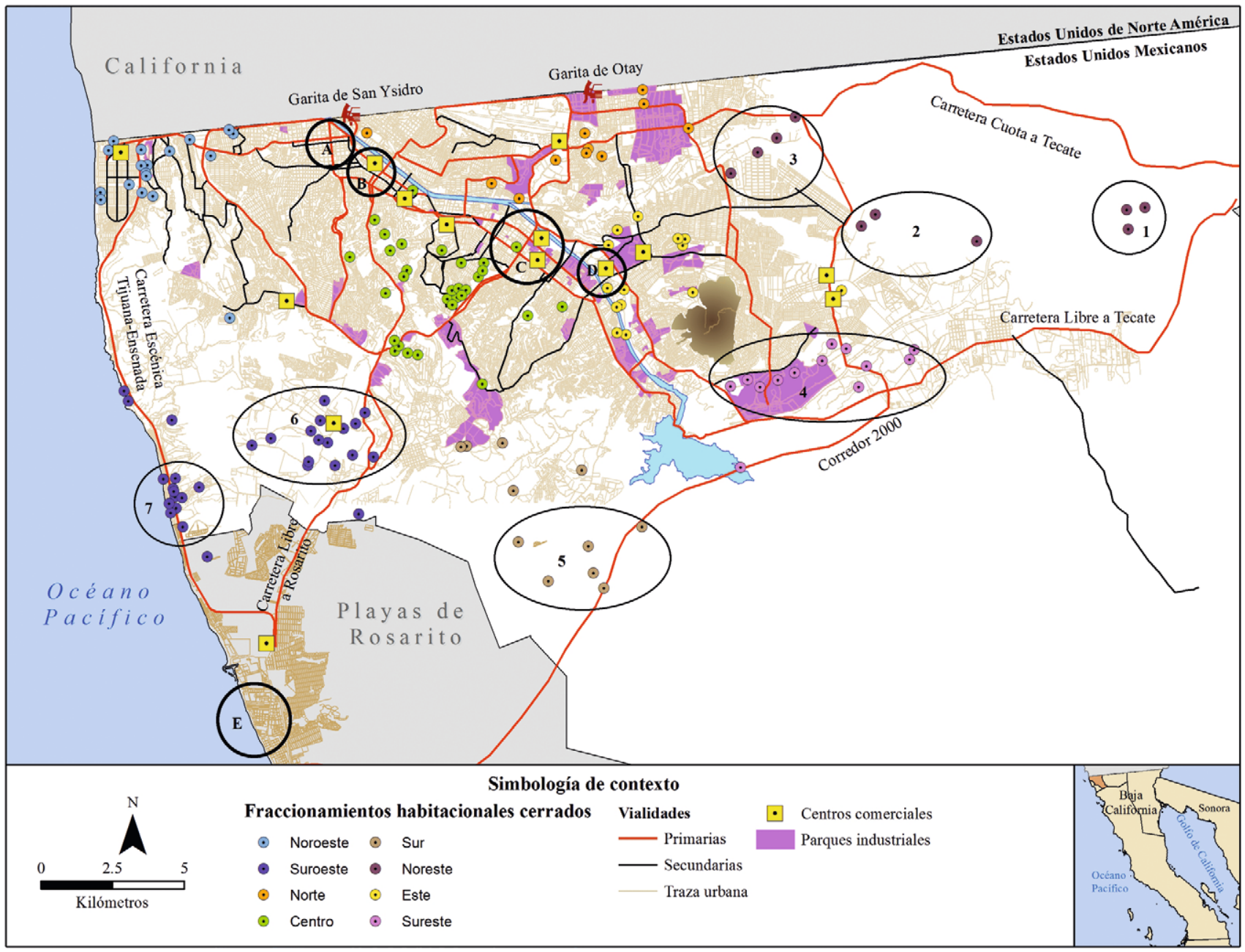

- Figura 11. Mapa general de desarrollos habitacionales cerrados, por zonas geográficas y distancias a principales centros de actividades en la ciudad de Tijuana, B.C. (1990-2010).

FuENTE: Elaborado en base al Sistema para la Consulta de Información Central (SINCE) y Censos Generales de Población y Vivienda, 1990, 2000, 2010, INEGI. Departamento de Administración Urbana. Secretaría de Desarrollo Urbano XIX Ayuntamiento de Tijuana. 
Tabla 5. Número de desarrollos habitacionales cerrados según zonas, número de viviendas y superficie en la ciudad de Tijuana, B.C.

\begin{tabular}{|c|c|c|c|}
\hline Zonas & Número de fraccionamientos & Número de viviendas & Superficie $\mathrm{m}^{2}$ \\
\hline Noroeste & 18 & 2.671 & 1.407 .676 \\
\hline Suroeste & 35 & 9.385 & 2.486 .934 \\
\hline Norte & 9 & 1.078 & 386.434 \\
\hline Centro & 28 & 270 & 500.544 \\
\hline Sur & 14 & 51.000 & 10.165 .336 \\
\hline Noreste & 12 & 19.818 & 3.302 .002 \\
\hline Este & 16 & 602 & 1.091 .879 \\
\hline Sureste & 15 & 13.575 & 3.151 .103 \\
\hline Total & 147 & 98.399 & 22.491 .909 \\
\hline
\end{tabular}

FuENTE: Dirección de Administración Urbana. Secretaría de Desarrollo Urbano, XIX Ayuntamiento de Tijuana, B. C. 2009.

Tabla 6. Distancia lineal entre Zonas de atracción urbana y zonas de agrupamiento de fraccionamientos habitacionales cerrados en Tijuana, B.C. 2010

\begin{tabular}{|c|c|c|c|c|c|}
\hline \multirow[t]{2}{*}{ Zonas } & A. Zona Centro & B. Zona Río & C. Zona 5 y 10 & $\begin{array}{l}\text { D. Zona Blvd. } \\
\text { Insurgentes } \\
\text { (Macroplaza) }\end{array}$ & E. Zona Rosarito \\
\hline & Distancia $(\mathrm{km})$ & Distancia (km) & Distancia $(\mathrm{km})$ & Distancia (km) & Distancia (km) \\
\hline 1. Zona Noreste Villas del Campo & 42,6 & 39,7 & 34 & 28,7 & 51,6 \\
\hline $\begin{array}{l}\text { 2. Zona Noreste Villas Residencial del } \\
\text { Bosque }\end{array}$ & 26,8 & 23,8 & 19,6 & 10,2 & 43,6 \\
\hline 3. Zona Noreste Lomas Terrabella & 20,5 & 17,5 & 12,3 & 7,7 & 47,1 \\
\hline 4. Zona Sureste Cañadas del Florido & 22 & 19,1 & 14,3 & 8,8 & 39,7 \\
\hline 5. Zona Sur Hacienda Las Delicias & 29,2 & 26,3 & 18,1 & 16,8 & 25,8 \\
\hline 6. Zona Suroeste Santa Fe & 13,3 & 11,5 & 10,2 & 14,4 & 14,4 \\
\hline 7. Zona Suroeste San Antonio del Mar & 20,9 & 24,7 & 29,2 & 31,6 & 12,4 \\
\hline
\end{tabular}

Fuente: Programa Google Maps 2012.

Sin duda, una de las principales afectaciones derivadas de la distribución geográfica de los desarrollos del periurbano en la ciudad, se refiere a las distancias y los tiempos que cotidianamente sus residentes deben efectuar para satisfacer algunas de sus necesidades en los centros de atracción. En la tabla 6 se señalan con letras estas zonas de atracción urbana, como son: Zona Centro, Zona Río Tijuana, Zona 5 y 10, Zona Blvd. Insurgentes (Macroplaza) y Zona Rosarito. Estas zonas representan centros de consumo de servicios y bienes, esparcimiento $y$, sobre todo, algunas representan puntos de confluencia con un gran número de rutas de transporte público y que se distribuyen al resto de la ciudad, incluyendo a las periferias. Por otra parte, en la misma tabla están señaladas con número las zonas de agrupación de la mayoría de los desarrollos habitacionales y que se localizan en las partes más alejadas.
Debido a esta situación, muchos de los recorridos que realiza la población desde cualquiera de los puntos, requieren de transbordo de rutas, incrementando con ello el tiempo invertido en los traslados. En cuanto a las rutas de los automovilistas, éstas no se enlazan de manera directa, sino a través de interconexiones a vialidades de distintas jerarquias; lo que también incrementa las distancias que se recorren, especialmente en los traslados de la periferia a las zonas centrales o viceversa, o bien, entre periferias. Así, en la tabla 6 se puede observar como las zonas periurbanas que se encuentran a mayor distancia de los centros son la Zona Noreste Villas del Campo, en segundo lugar, la Zona Sur Hacienda las Delicias y en tercero, la Zona Noreste Villas del Bosque, registrándose recorridos de hasta de más de 50 kilómetros (Véase tabla 6). 


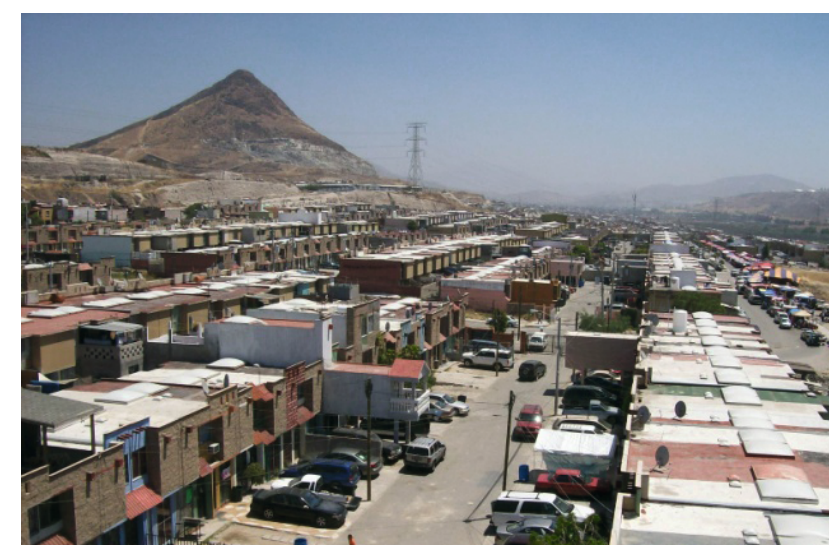

\ Figura 12. Cañadas del Florido (Zona Este). Tijuana.

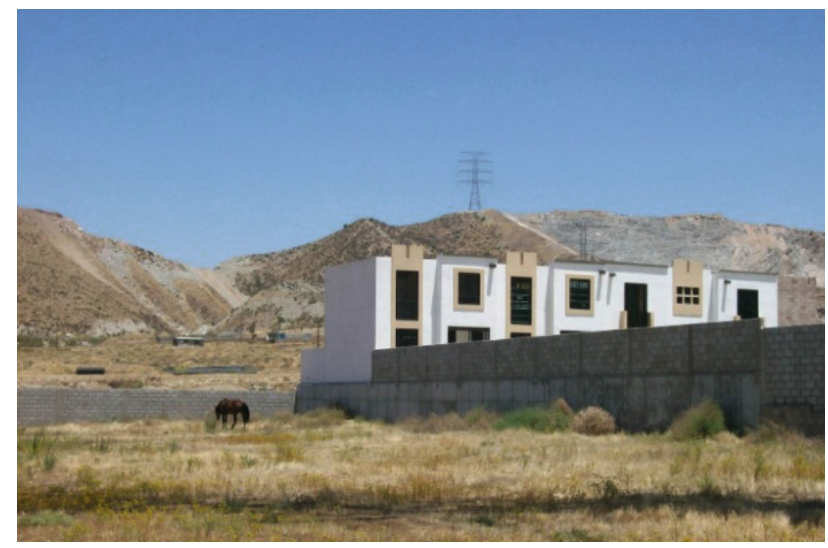

\ Figura 14. Residencial Habitat Piedras Blancas (Zona Sureste). Desarrollo aislado mezclado con uso de suelo rural.

\section{CONCLUSIONES}

En la estructura intraurbana de la ciudad de Tijuana se destaca la extensa área del periurbano, la cual se distingue por una importante dinámica de transformación. Dentro de su multifuncionalidad predomina la función o uso de suelo residencial, mismo que se expandió aceleradamente de manera dispersa y desordena, sobre todo durante las últimas décadas del siglo anterior. La influencia de su posición geopolítica como centro de cruce internacional de bienes, servicios y personas, ha sido un factor importante en el proceso de reestructuración del espacio urbano. Otros factores, como los cambios relacionados con la globalización y algunos propios de la ciudad, han intensificado fenómenos como una expansión periurbana inmersa en procesos de operiurbanización dispersa o difusa y fragmentada.

Gran parte de las transformaciones que se observan en la franja periurbana, y que tienen conexión con procesos de reestructuración en la ocupación del suelo, se relacionan también con fenómenos como la movilidad residencial de algunas clases sociales del centro hacia las periferias, la

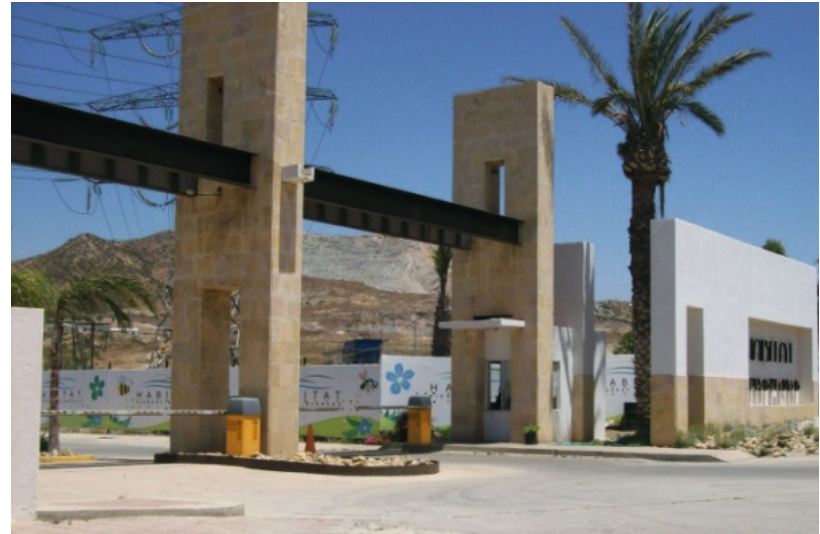

A Figura 13. Residencial Habitat Piedras Blancas (Zona Sureste).

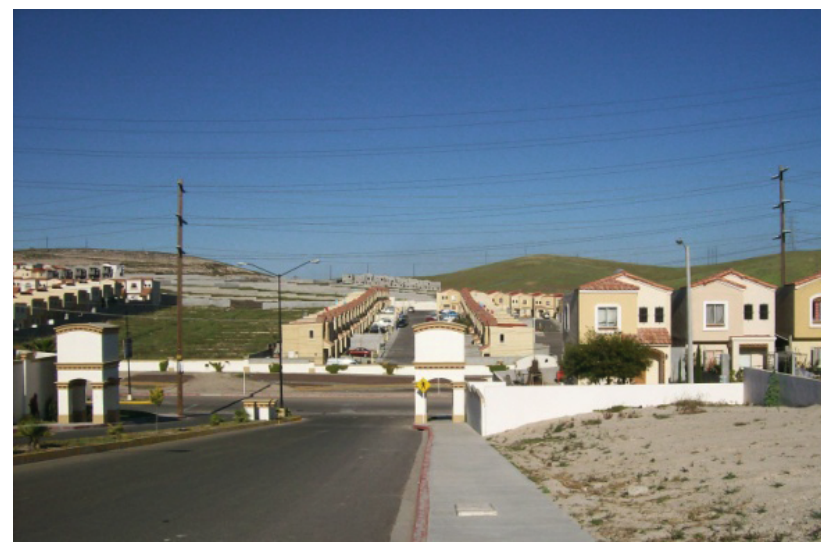

\ Figura 15. Residencial Barcelona (Zona Sur). Desarrollo habitacional de interés medio.

construcción de complejos cerrados de viviendas dirigidos a diferentes grupos sociales, la invasión de predios no accesibles o ilegales por sectores de clases bajas o migrantes. Además de las obras de infraestructura que facilitan el desarrollo de actividades productivas que, en general, motivan el desarrollo de toda clase de usos de suelo.

En la función residencial del periurbano de Tijuana destaca el tipo unifamiliar y multifamiliar con régimen de copropiedad, por lo general de baja densidad y de alto consumo de suelo. Sin embargo, el surgimiento de los modelos de alta concentración de viviendas en espacios reducidos muestra un entorno de amplias "islas residenciales" que forman parte de un fenómeno de fragmentación del espacio que se observa en estos territorios, con desarrollos o fraccionamientos de cientos y miles de viviendas con características de enclaustramiento. Estos fraccionamientos responden a modalidades nacionales e internacionales de capital privado inmobiliario, que reacciona ante la creciente demanda de vivienda y aprovecha las condiciones del mercado del suelo en la franja periurbana, asi como las regulaciones locales que facilitan su expansión a través de nuevas instancias de poder. Este pro- 
ceso equivale a una transferencia de la gestión del desarrollo urbano por parte del gobierno a la inversión privada.

En los primeros diez años (1990-1999) de la proliferación de desarrollos habitacionales cerrados en Tijuana se tenían registrados 31. Once años después, para el año 2010, ya se contaba con 116 desarrollos más, haciendo un total de 147, lo que nos permite observar un incremento del 374\%. El gran impulso de este modelo habitacional se produjo durante los primeros años de este siglo, con pequeños conjuntos de tipo residencial turístico, ubicados a lo largo de la línea costera y otros dirigidoa grupos de altos ingresos dispersos alrededor de la zona central. Al mismo tiempo, se fueron proyectando los primeros grandes complejos de cientos de viviendas de interés social y que se identificaban por modelos de viviendas de estructura homogénea, de tamaño reducido y construcciones de poca calidad.

Lo que ha distinguido a este fenómeno en Tijuana es que a partir de los últimos 9 a 10 años, el incremento del número de desarrollos ha sido muy alto. Se ha privilegiado una ubicación demasiado distante de los principales recursos urbanos, como son el acceso adecuado a los sistemas de vialidades y transporte público, así como a las zonas de actividades laborales, de consumo y de servicios.
El surgimiento de los enormes proyectos de miles de viviendas comienza a prosperar sobre las zonas con mayor disponibilidad de suelo legal, apto y de bajo precio, a partir del año 2005. Esos proyectos se localizan en las zonas más externas del periurbano.. En promedio, los residentes de tres de los grupos de fraccionamientos cerrados más distantes, deben recorrer entre 25 y 43 kilómetros de trayecto para llegar a las principales zonas centrales y repetirlo de regreso a sus viviendas. Esta situación representa un importante detrimento en la calidad de vida de los residentes, tomando en cuenta que, dependiendo del tipo de transporte y los horarios de traslado, el tiempo de los recorridos puede elevarse al rango de una a tres o cuatro horas.

Sin duda, este modelo habitacional periurbano no escapa a una realidad globalizada, la que refuerza estándares de convivencia y consumo, generalmente dirigido por el capital privado inmobiliario y sus intereses. Pero que ante factores como la búsqueda de seguridad, estatus y calidad de vida a precios accesibles, gran parte de los habitantes de estos asentamientos se ven afectados negativamente $y$, probablemente, sin alternativas a corto plazo ante la presión del actual modelo de desarrollo urbano globalizado.

\section{BIBLIOGRAFÍA}

AgUILAR, G., Las Grandes aglomeraciones y su periferia regional, experiencias en Latinoamérica y España. México, Editorial Miguel Ángel, Porrúa, 2006.

Alegria, T. y Ordoñez, G., Legalizando la ciudad. Asentamientos informales y procesos de regularización en Tijuana. México, El Colegio de la Frontera Norte, 2005.

ÁvILA, H., "Ideas y planteamientos teóricos sobre los territorios pertúrbanos. Las relaciones campo-ciudad en algunos países de Europa y América", Investigaciones geográficas, Boletín del Instituto de Geografía, 45, México (2001), pp. 108-127.

BAUER, G., ROUX,J., La rurbanisation ou la ville éparpillée, 1976, pp. 90, Editions du Seuil, Paris. En Berger, (1980).

BAZANT, Periferias Urbanas: expansión urbana incontrolada de bajos ingresos y su impacto en el medio ambiente. México, Trillas, 2001.

Berger, M., "Rurbanisation: Analyse des espaces ruraux péri-urbaines", L'Espace Géographique, núm. 4, (1980), pp. 300- 313.

Blakel, E. y SNyder, "Fortress Communities: The walling and Gating of American Suburbs", en Cabrales y Canosa, (2001)

CABRALES B. y CANOSA Z., "Segregación residencial y fragmentación Urbana: Ios fraccionamientos cerrados en Guadalajara”. Espiral: Estudios sobre estado y sociedad. Guadalajara, México, vol. VII núm. 20. (2001), pp.223-253.

CALDEIRA, T., "Fortified enclaves: the new urban segregation", 1999, en Janoschka, Michael, "El nuevo modelo de la ciudad latinoamericana: fragmentación y privatización". Revista EURE vol., 28 núm. 85. Santiago de Chile, (2002).

CuRTit, G., "Ciudad, Gestión local y nuevos desafíos ambientales: reflexiones en torno a las políticas neoliberales y sus efectos sobre nuestros territorios". $1^{\text {a }}$ ed, 2003, Buenos Aires: Espacio, en Cardoso, André y Ortiz Julia, Peri urbanización, segregación social y fragmentación territorial, Argentina, Universidad Nacional de Tucumán, (2002)
Davis, M., "City of Quartz: Excavating the future in Los Angeles, Londres: Verso, en Janoschka, M., "El nuevo modelo de la ciudad latinoamericana: fragmentación y privatización". Revista EURE, vol., 28 núm. 85. Santiago de Chile, (2002).

Dear, M., The Postmodern Challenge: Reconstructing Human Geography, Transactions of the Institute of British Geographers, 1988 vol. 13 pp. 262-274, en Janoschka, Michael, "El nuevo modelo de la ciudad latinoamericana: fragmentación y privatización". Revista EURE, Santiago de Chile, vol., 28 núm. 85, (2002).

De Mattos, C., Transformación de las ciudades latinoamericanas. ¿lmpactos de la globalización?, editor invitado, Scielo, EURE. Santiago de Chile, vol. 28, núm. 8, (2002), pp. 1-5.

FERNANDEZ, G., Los aspectos funcionales de los espacios periurbanos. IX Coloquio de Geografía. Tomo II. Ponencias. Editorial AGE. Murcia, (1985).

Friedman, J. y Goetz, W., World City Formation: An Agenda for Research and Action, International Journal of Urban and Regional Research, vol.6, No. 2, (1982), pp. 319.

Griffin, E., y Ford, L., A model of Latin American City Structure, Geographical Review, vol. 70, en ZARATE, M. Antonio, El espacio interior de la ciudad. Sintesis Editorial. Madrid, España, (1991).

Gobierno del Estado de Baja California, Plan Sectorial de Vivienda del Estado de Baja California 2009-2013. Mexicali, Baja California, (2008).

Hidalgo, R., Álvarez C., y Salazar, "Los condominios y urbanizaciones cerradas como nuevo modelo de construcción del espacio residencial en Santiago de Chile (1992 - 2002)". Revista Scripta Nova, Universidad de Barcelona, vol. 7, núm. 146 (2003).

IMPLAN, (Instituto Municipal de Planeación) Actualización del Programa de Desarrollo Urbano del Centro de Población de Tijuana, XIX Ayuntamiento de Tijuana, Baja California, (2009).

INEGI (Instituto Nacional de Estadística, Geografía e Informática), Sistema para la Consulta de Información Central (SINCE), México, (2000). 
INEGI (Instituto Nacional de Estadística, Geografía e Informática), Censos Generales de Población y Vivienda 1990, 2000, 2010 y II Conteo de Población y Vivienda 2005. México.

JANOSHKA, M., "El nuevo modelo de la ciudad latinoamericana: fragmentación y privatización", (2002). Revista EURE, Santiago de Chile, vol., 28 núm. 85, pp. 1-20.

Low, S., "On the Plaza. The Politics of Public Space and Culture", Austin: University of Texas Press, en JANOSCHKA, Michael, "El nuevo modelo de la ciudad latinoamericana: fragmentación y privatización". Revista EURE, vol., 28 núm. 85. Santiago de Chile, (2002).

MARTIN, R., "Cambios en la producción del espacio urbano residencial en la periferia de la ciudad metropolitana de Buenos Aires. Un estudio de caso en el municipio de Tigre". Estudios Demográficos y Urbanos, México, vol. 21, núm. 3(63), (2006) pp. 701-729.

Monclus, F. Javier, "La ciudad dispersa", Revista EURE, Santiago de Chile, 2000, vol. 26 num.77. pp. 223.

Organización de las Naciones Unidas, Segunda Conferencia de las Naciones Unidas sobre Asentamientos Humanos. Programa Habitat II, Turquia, Estambul, (1996).

SABAtINI, F., "La segregación social del espacio en las ciudades de América Latina", Documentos de trabajo, Serie Azul, núm. 35, Instituto de Estudios Urbanos y Territoriales, Pontifica Universidad Católica de Chile,(2003), en CABRALES B, "Ciudades Cerradas, Libros abiertos", Red Nacional de Investigaciones Urbanas" (RNIU), Ciudades ,núm.5.,Puebla, México, (2003)
SabatinI, F., Caceres, G. y Cerdan, J., "Segregación residencial en las principales ciudades chilenas: tendencias de las tres últimas décadas y posibles cursos de acción", en Janoschka, Michael, "El nuevo modelo de la ciudad latinoamericana: fragmentación y privatización". Revista EURE, Santiago de Chile, vol., 28 núm. 85, (2002).

SAHOPE, (Secretaria de Asentamientos humanos y Obras Publicas del Estado), Esquema Urbano de la Ciudad de Tijuana, Gobierno del Estado de Baja California. Mexicali, Baja California, (1991)

SojA, E., "Geografias pós- modernas", Río de Janeiro: Jorge Zahar, en Martin, Ríos, "Cambios en la producción del espacio urbano residencial en la periferia de la ciudad metropolitana de Buenos Aires. Un estudio de caso en el municipio de Tigre". Estudios Demográficos y Urbanos, México, vol. 21, núm. 3(63), (2006) pp. 701-729.

Zarate, M. Antonio, El espacio interior de la ciudad, Síntesis Editorial. Madrid, España, (1991).

Páginas de Internet:

http://www.conapo.gob.mx/

http://www.inegi.org.mx/

http://www.bajacalifornia.gob.mx

http://www.tijuana.gob.mx/

http://www.un.org/spanish/conferences/habitat.htm\#inicio

http://www.tijuana.gob.mx/Leyes/pdf2011/leyes/LEYEDIFI_11JUL2008. pdf 
